\title{
Theoretical investigation on the optoelectronic properties of non-centrosymmetric D-A-D hexaazatriphenylene derivatives for photovoltaic applications
}

\author{
A. El alamy ${ }^{1}$, A. Amine ${ }^{1}$, S.M. Bouzzine ${ }^{2,3}$, M. Hamidi ${ }^{3}$, M. Bouachrine ${ }^{4, *}$ \\ ${ }^{1}$ LCBAE/CMMBA, Faculty of Science, Moulay Ismail University, Meknes, Morocco \\ ${ }^{2}$ Centre Régional des Métiers d'Education et de Formation, BP 8, Errachida, Morocco \\ ${ }^{3}$ Equipe d'Electrochimie et Environnement, Faculté des Sciences et Techniques, Université Moulay Ismaïl, \\ B.P. 509 Boutalamine, Errachidia, Morocco \\ ${ }^{4}$ ESTM, Moulay Ismail University, Meknes, Morocco.
}

\begin{abstract}
In this work, we report theoretical analysis on the geometries and optoelectronic properties of a family of ambipolar donor-acceptor-donor (D-A-D) as new conjugated compounds based on hexaazatriphenylene (HAT) derivatives synthesized by Rafael Juarez et al.. The theoretical ground-state geometry and electronic structure of the studied molecules were investigated by density functional theory (DFT) method at Becke's three-parameter functional and Lee- Yang-Parr functional (B3LYP) level with 6-31G (d) basis set. The highest occupied molecular orbital (HOMO), lowest unoccupied molecular orbital (LUMO), gap energy and the open-circuit voltage (Voc) of the studied compounds are calculated and discussed. The obtained results show that these compounds can be used in organic photovoltaic devices as an active layer for organic solar cell..
\end{abstract}

Keywords: $\pi$-conjugated molecules, hexaazatriphenylene (HAT), optoelectronic properties, DFT, HOMO/LUMO.

\section{Introduction}

Polycyclic aromatic hydrocarbons (PAHs, also polyaromatic hydrocarbons) are organic compounds composed of two or more fused aromatic rings with delocalized electrons. PAHs are often found naturally in combustion residues but, analytically pure and discrete PAHs are obtained only through synthesis ${ }^{1}$.

Most PAHs are also fluorescent, emitting characteristic wavelengths of light when excited ${ }^{2}$. The extended $\pi$-electronic structures of PAHs lead to these spectra, certain large PAHs also exhibit semiconducting and other behaviors ${ }^{3,4}$. Thanks to their optoelectronic and photovoltaic properties, PAHs belong to a class of functional organic compounds with increasing importance in organic electronics applications as organic field effect transistors (OFETs) ${ }^{5,6}$ and in photovoltaic devices as organic solar cell ${ }^{7}$.

Hexaazatriphenylene (HAT) is a disc like heterocycle electron acceptor, thanks to its $\mathrm{C}_{3}$ symmetry and six nitrogen atoms that exhibit excellent coordination ability to transition metal ions, HAT has been widely used as a ligand in coordination chemistry ${ }^{8}$. Moreover, Hexaazatriphenylene (HAT) derivatives have recently attracted attention as candidates materials for organic electronic and photovoltaic applications because of their easy synthetic accessibility 9,10, diversity in peripheral functionality, electron deficiency, n-type semiconductor and of their rigidity due to their high aromaticity ${ }^{11}$. The introduction of electron donor groups in HAT system (as D-A-D structure) offers valuable advantages to electrontransporting materials improving their optoelectronic and photovoltaic properties.

In this work, a theoretical study of four non-centrosymmetric molecules (with the structure donor-acceptor-donor (D-A-D)) based on hexaazatriphenylene (HAT) derivatives prepared by Rafael Juarez et al. ${ }^{12}$ (see Fig.1); M1 (9,10Diamino-1,4,5,8-tetraazaphenanthrene), M2 (2,3-bistrans[2(4-hexyloxyphenylene)-vinylene]hexaazatriphenylene), M3 and M4 having electron donor moieties; diamino, dibutylaminobenzene, hexyloxybenzene and the tetrathiafulvalene respectively, with the presence of alkyl chains on the peripheral donor

* Corresponding author: M. Bouachrine

E-mail address: bouachrine@gmail.com

DOI: http://dx.doi.org/10.13171/mjc44/015020713/bouachrine 
moieties of the molecules M2, M3 and M4 allows to obtain soluble materials.

The geometric and the optoelectronic properties of these compounds were studied by density functional theory DFT and ZINDO/DFT calculations at B3LYP functional with 6-31G(d) basis set. The theoretical knowledge of the HOMO, LUMO, Voc and gap energies of the studied compounds have been calculated and, reported and compared with experimental results. The obtained results suggest these compounds as good candidates for optoelectronic applications.
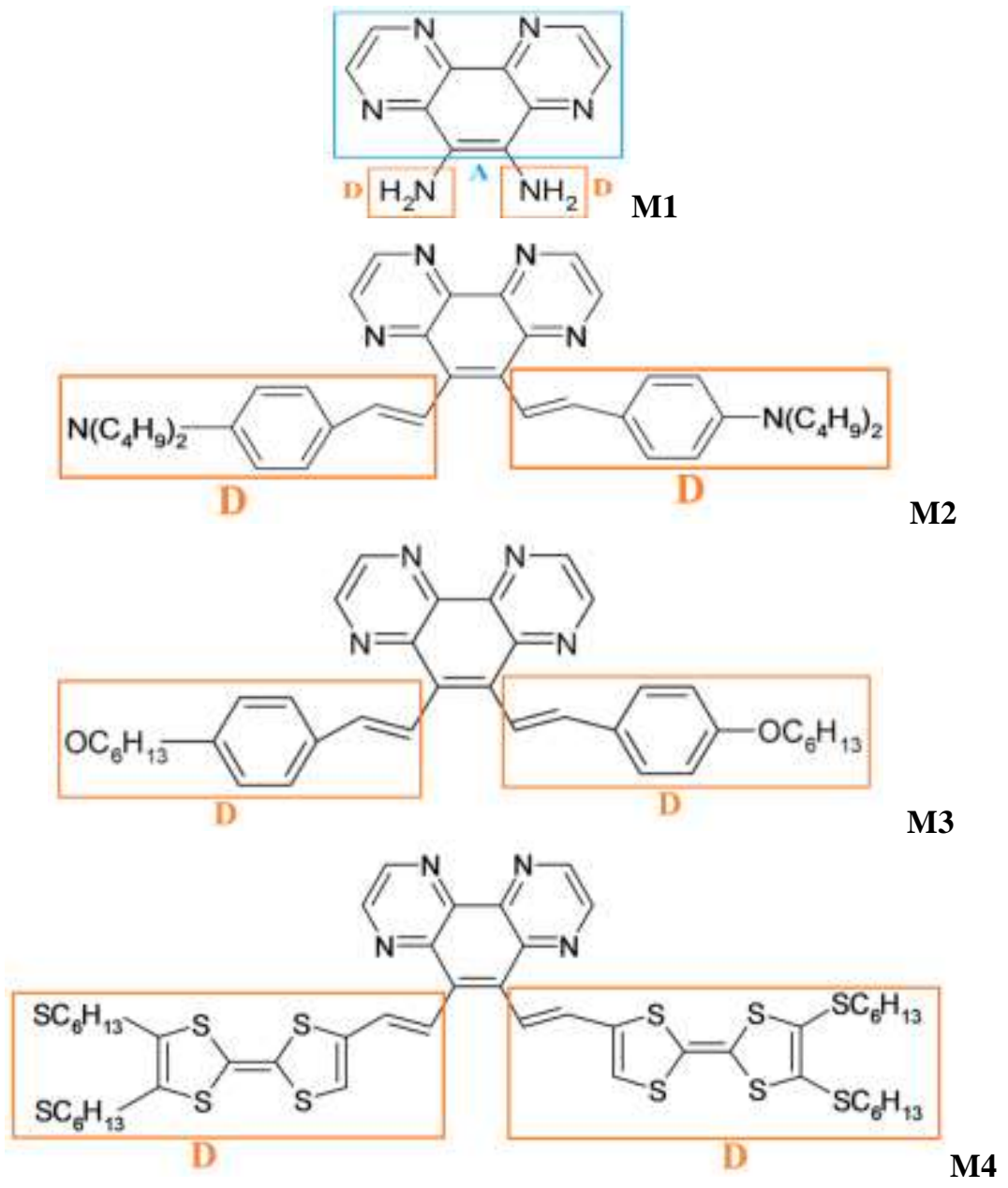

Figure.1. Chemical structures of the studied molecules with their electron donor moieties D.

\section{Computational methodology}

DFT method with Becke's three-parameter functional and Lee-Yang-Parr functional (B3LYP) ${ }^{13}$ was used to study these compounds. The 6-31G(d) basis set was used for all calculations ${ }^{14}$. The geometric structures of all molecular systems were calculated using the Gaussian09 program ${ }^{15}$. We have also examined the HOMO, LUMO levels and the gap energy (Egap is calculated as the difference between the HOMO and LUMO energies) for the stable structures. The vertical excitation energies, oscillator strengths and the optical transitions (in the UV-Vis-NIR region) were calculated using ZINDO method starting with the fully optimized geometries obtained at B3LYP/6-31G(d) levels ${ }^{16}$.

\section{Results and discussion}

\section{Structure and geometric properties}

The optimized structures of our studied molecules are depicted in Figure. 2 and were obtained by B3LYP function combined with 6-31G (d) basis set using Gaussian 09 program. It was found in other works that the DFT-optimized geometries were in excellent agreement with the data obtained from $X$ ray analyses ${ }^{17}$. The results of the optimized structures for all studied compounds show that they have similar conformations (quasi planar conformation) (see Figure. 2). 

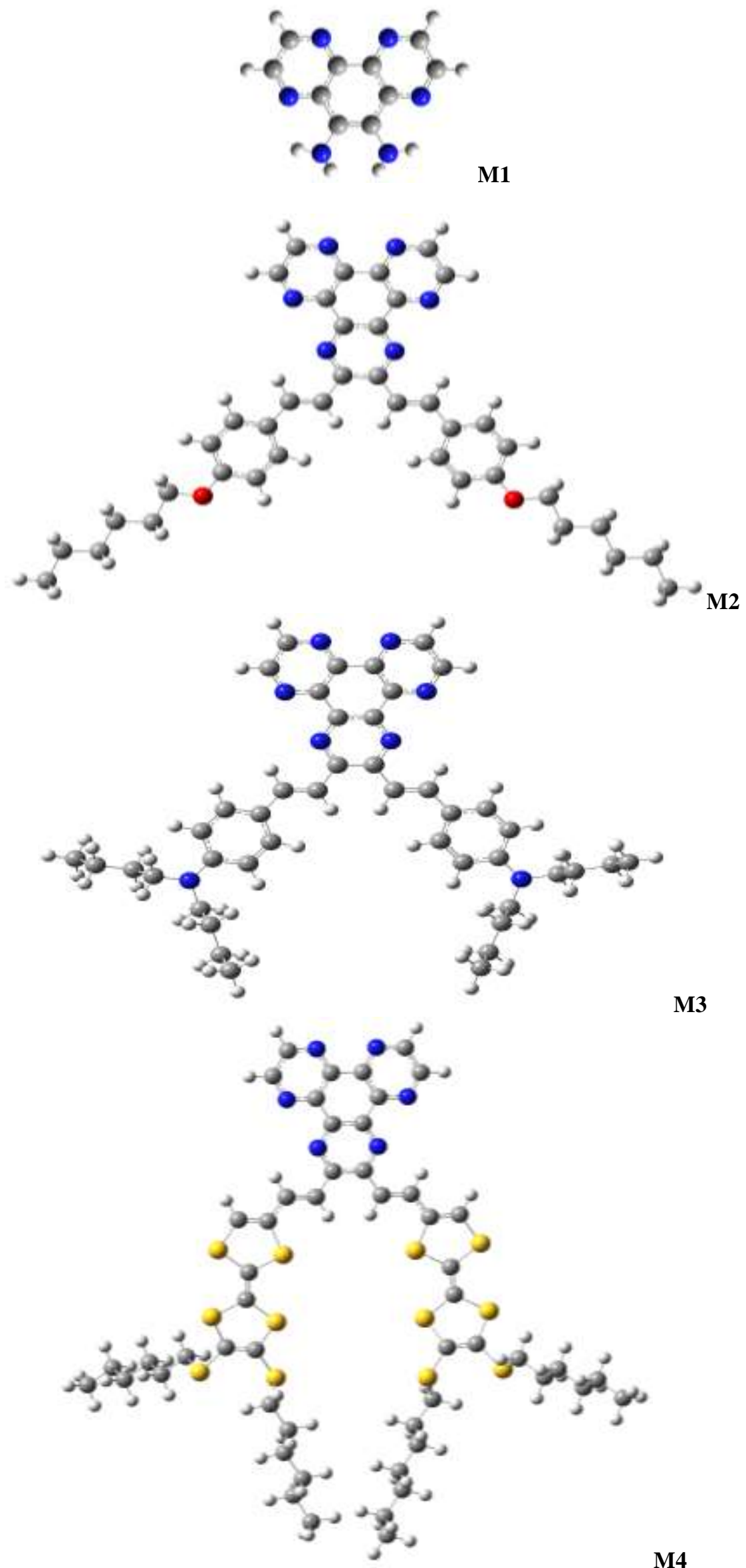

Figure.2. Optimized structures of the studied molecules obtained by B3LYP/6-31G (d) level. 
Optoelectronic properties

To study the electronic properties of these conjugated materials, it is very important to examine their HOMO and LUMO levels because the relative ordering of occupied and virtual orbitals provides a reasonable qualitative indication of excitation properties 18, and the ability of electron hole transport. As shown in Fig.3, the HOMOs possess

HOMO

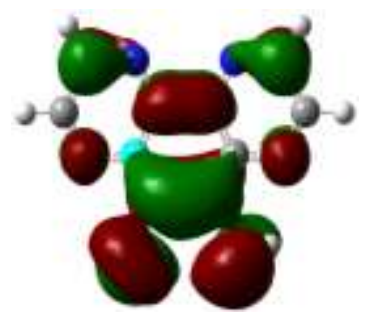

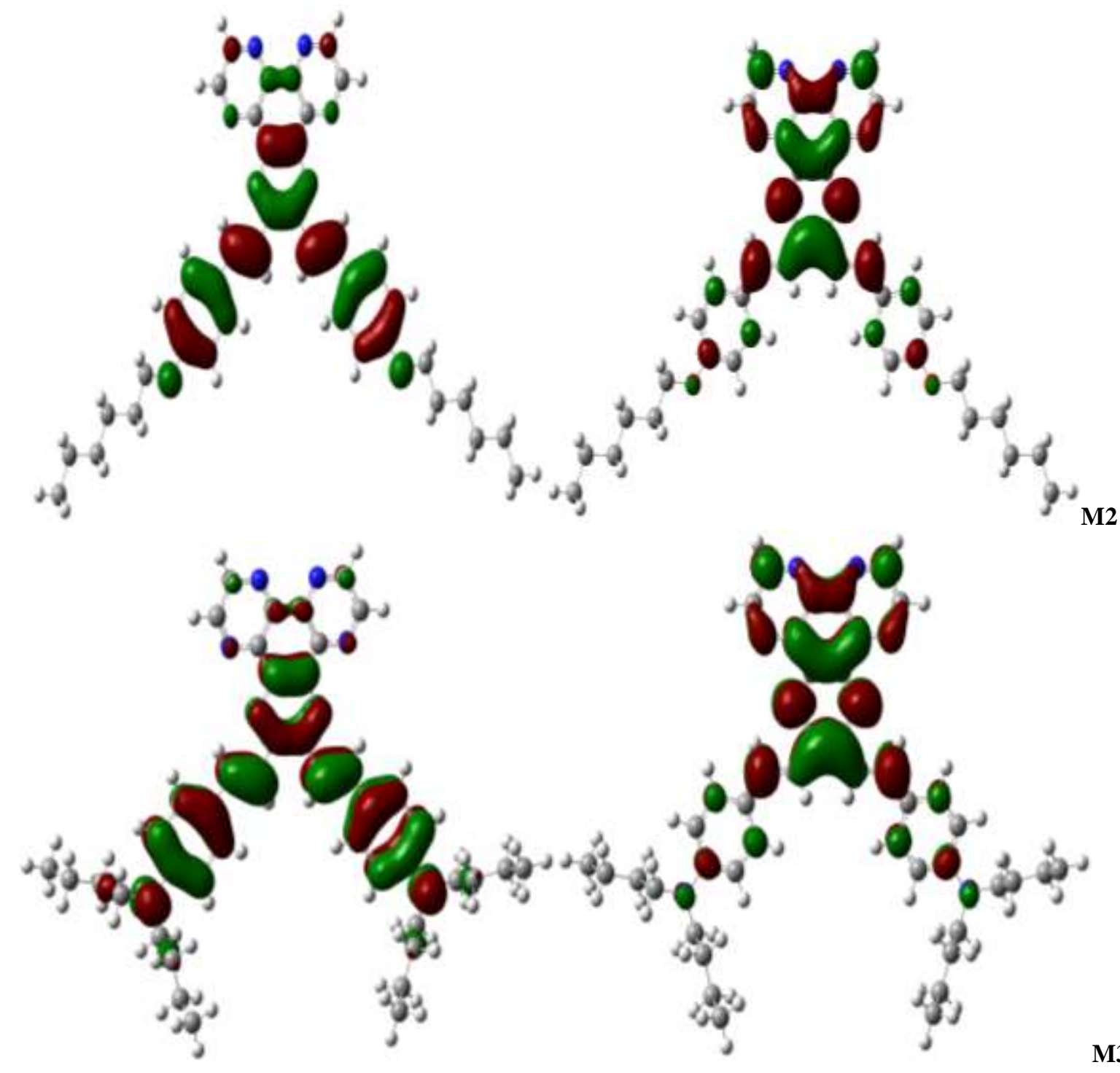

generally a $\pi$-anti-bonding character between the consecutive subunits and are localized mainly on the donor moiety. The LUMOs of all oligomers instead, are localized mainly on the HAT system and show a $\pi$-bonding character between the subunits. This distribution of HOMO and LUMO is expected to favor the charge transfer along the molecular chain.

\section{LUMO}

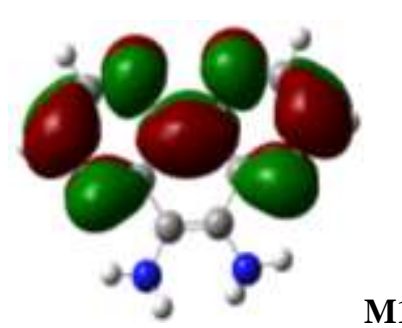

M1 


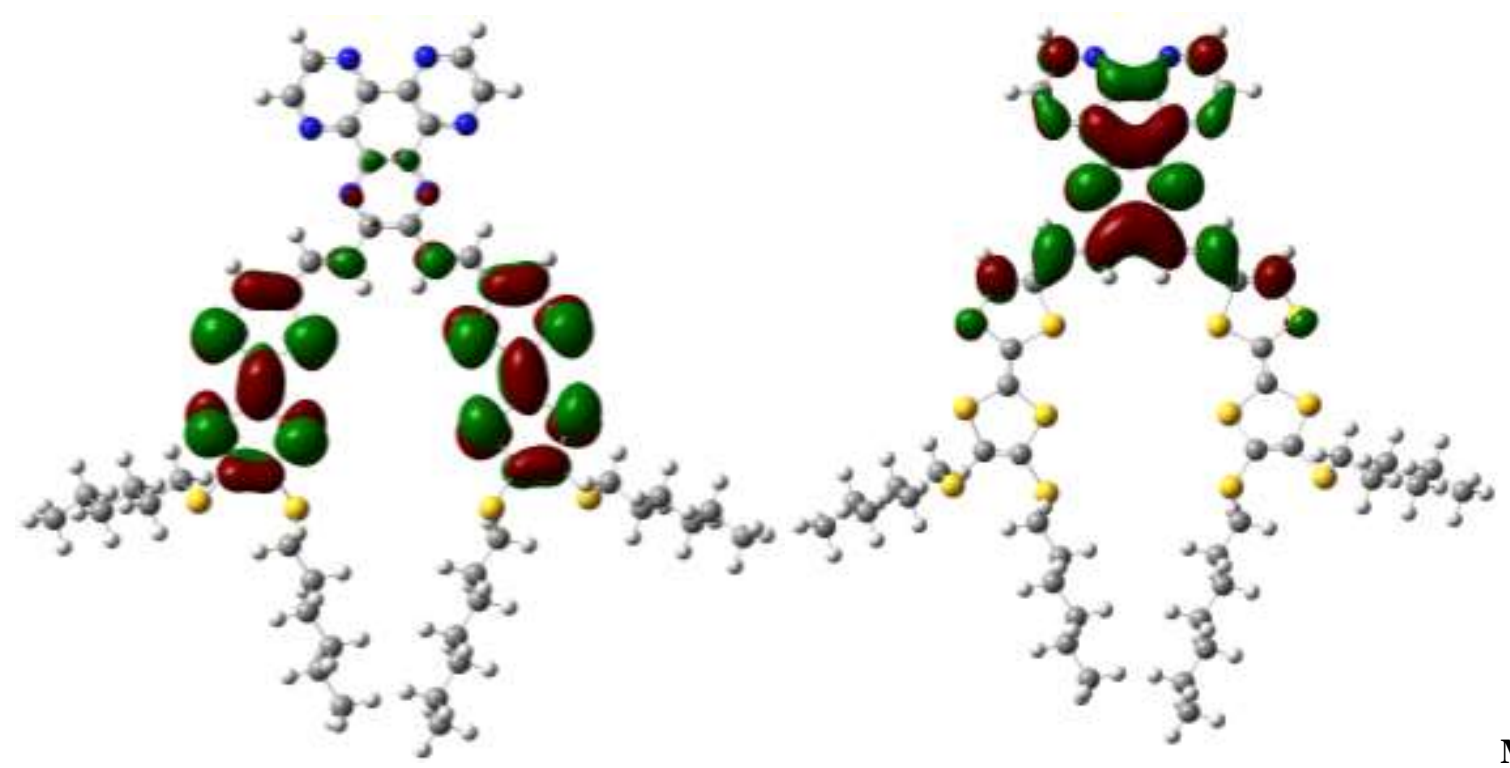

Figure 3. The contour plots of HOMO and LUMO orbitals of the studied compounds

By using DFT/B3LYP/6-31G (d) method for all molecules; the obtained electronic parameters (HOMO, LUMO and gap energy) values of the studied compounds are summarized in table 1 . In comparison with $\mathrm{M} 1$, we notice a destabilization of the HOMO and stabilization of LUMO levels of M2, M3 and M4. We can remark also a slight difference in the HOMO and LUMO energies of the studied compounds (see Table 1 and Fig. 4).

On the other hand, as shown in Table 1, the gap energy decreases going from M1 to M4 in the following order M1 $(3.30 \mathrm{eV})>\mathrm{M} 2(2.44 \mathrm{eV})>\mathrm{M} 3$ $(2.02 \mathrm{eV})>\mathrm{M} 4(1.78 \mathrm{eV})$. This is due to the presence of the electron-donating groups (hexyloxybenzene in M2, dibutylaminobenzene in M3 and tetrathiafulvalene in M4) and to the conjugation lengths in these molecules (increase of $\pi$-delocalization). We can see that the M4 has the lowest energy gap $(1.78 \mathrm{eV})$; this can be attributed to the strongest donor character of the tetrathiafulvalene moiety.

Interestingly, for our compounds, the obtained gap values (ranging from 1.78 to $3.30 \mathrm{eV}$ ) are sufficient to consider their applications in optoelectronic devices.

Table 1: Electronic parameters (HOMO, LUMO, Gap) obtained by B3LYP/6-31G (d) of the studied molecules and experimental energy gap Egap (exp).

\begin{tabular}{lllll}
\hline Compounds & EHOMо $_{(\mathbf{e V})}$ & ELumo $_{\text {(eV) }}$ & Egap $(\mathbf{e V})$ & ${\text { Egap }(\exp )^{12}}^{12}$ \\
\hline M1 & -5.19 & -1.89 & 3.30 & - \\
M2 & -5.14 & -2.69 & 2.44 & 2.53 \\
M3 & -4.61 & -2.58 & 2.02 & 2.14 \\
M4 & -4.68 & -2.89 & 1.78 & 1.87 \\
\hline
\end{tabular}

Comparing calculated and experimental gap values (see Table 1), we noted an agreement between calculated and experimental results. Therefore, the DFT theoretical calculations give a good description of the electronic properties of the studied compound and can be employed to predict these properties for other organic materials. 


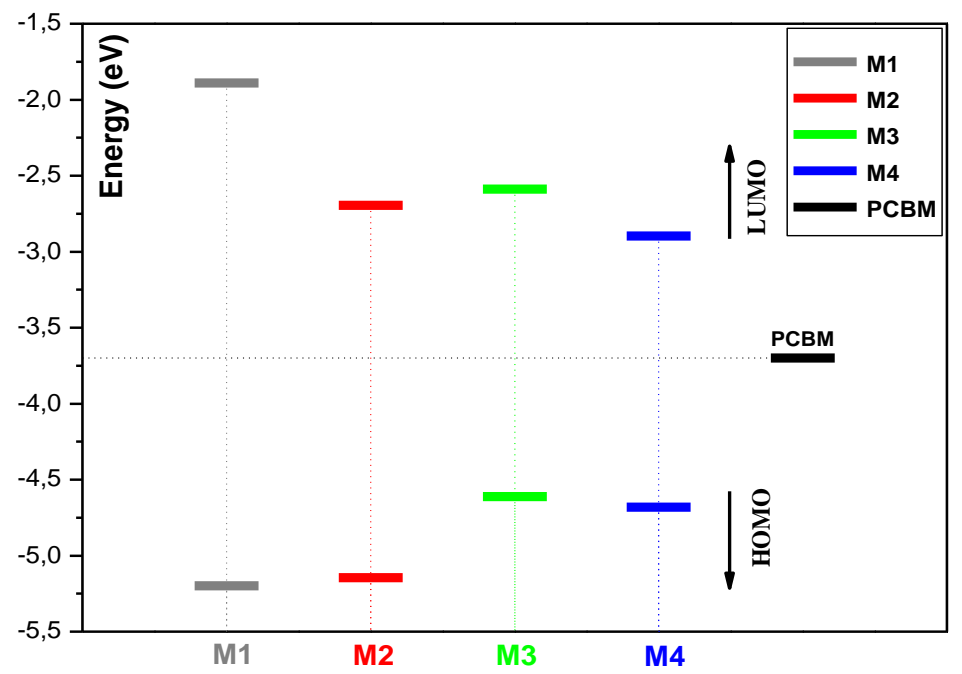

Figure 4. Chematic energy levels of the studied compounds and the LUMO energy of PBCM.

\section{Photovoltaic performances}

To study the photovoltaic properties of these compounds, the HOMO and LUMO energy levels are very important parameters to determine whether the effective charge transfer will happen between donor (the studied molecules) and acceptor [6.6]phenyl-C61-butyric acid methyl ester (PCBM) (substituted $\mathrm{C}_{60}$ ). Moreover, to evaluate the possibilities of electron transfer from the excited studied molecules to the conduction band of the acceptor PCBM, the HOMO and LUMO levels were compared. As plotted in Fig. 4, we noted that the LUMO levels of the studied compounds are higher than that of PCBM $\left(\mathrm{E}_{\mathrm{LUMO}}=-3.7 \mathrm{eV}^{19}\right)$, this suggests that the photoexcited electron transfer from the studied molecules to PCBM can be sufficiently efficient to be used in photovoltaic devices as active layer in Bulk heterojunction layer (BHJ) for organic solar cell.

Table 2. Energy Values of $\mathrm{E}_{\text {номо }}, \mathrm{E}_{\mathrm{Lumo}}$ and the Open Circuit Voltage Voc by eV.

\begin{tabular}{lllcc}
\hline Compounds & E $_{\text {Hомо }}(\mathrm{eV})$ & $\mathrm{E}_{\text {LUMO }}(\mathrm{eV})$ & Voc $(\mathrm{eV}) / \mathrm{PCBM}$ & $\alpha_{\mathrm{i}} *(\mathrm{eV}) / \mathrm{PCBM}$ \\
\hline M1 & -5.19 & -1.89 & 1.49 & 1.81 \\
M2 & -5.14 & -2.69 & 1.44 & 1.01 \\
M3 & -4.61 & -2.58 & 0.91 & 1.12 \\
M4 & -4.68 & -2.89 & 0.98 & 0.81 \\
PCBM & -6.10 & -3.70 & - & - \\
\hline
\end{tabular}

${ }^{*} \alpha_{i}=$ ELUMO (Mi) - ELUMO (PCBM); (The donor compounds are Mi, i=1-4).

Anther important photovoltaic parameter is the maximum open circuit voltage (Voc), which is calculated as the difference between HOMO energy of the donor and LUMO energy of the acceptor PCBM. The theoretical values of Voc have been calculated by the following expression ${ }^{20}$ :

$$
\mathrm{V}_{\text {ос }}=\mid \mathrm{E}_{\text {номо }} \text { (Donnor) }|-| \mathrm{E}_{\text {LUмо }} \text { (Acceptor) } \mid-0.3
$$

As summarized in Table 2, the calculated values range from $0.91 \mathrm{eV}$ to $1.49 \mathrm{eV}$ these values are sufficient to ensure an efficient electron injection. This suggests our molecules as good candidates for organic solar cells.

\section{Absorption properties}

Starting with optimized geometry obtained at B3LYP/6-31G(d); the ZINDO method has been used for all molecules $\mathrm{Mi}$ to obtain the energy of the singlet-singlet electronic transitions and to calculate the ultraviolet-visible (UV-Vis) spectra $(\lambda \mathrm{abs})$ and the oscillator strength (O.S) of the studied compounds. The values of these parameters and the corresponding simulated UV-Vis absorption spectra of $\mathrm{Mi}$, presented as oscillator strength against wavelength are shown in table 5 and Fig.5 respectively. We note that All electronic transitions are of $\pi-\pi^{*}$ type involving both subunits of the molecules, and that the higher oscillator strengths $(O . S)$ originate from $\mathrm{S}_{0} \rightarrow \mathrm{S}_{2}$ electronic transition for M1, M2 and M3 but, for M4 it originates from $\mathrm{S}_{0} \rightarrow \mathrm{S}_{1}$ transition. In addition, the excitation to the $\mathrm{S} 2$ state (and to S2 for M1) corresponds to the promotion of an electron from the HOMO to LUMO. Another considered point is that the position 
of $\lambda \max$ shows a bathochromic shift when passing from M1 to M3, which also can be seen, respectively in M1 (386.36 nm), M2 (395.88 nm) and M3 (412.08 $\mathrm{nm}$ ) due to the increase of the extended conjugation through the molecules and of the donor ability of the donor moiety. We note also that the experimental $\lambda \max$ values of M3 ( 480 nm) and M4 ( $340 \mathrm{~nm})$ are in agreement with the theoretical ones of M3(412.08 nm) and M4 (391.02 nm). This difference between theoretical and experimental values can be explained by the fact that the calculations assume that the molecules are in the vapour state. Finally, the procedures of DFT theoretical calculations give good descriptions of absorption properties of the studied compounds and can be employed to predict the optoelectronic characteristics for other materials.

Table 3. Data absorption spectra obtained by ZINDO method for the compounds studied in the optimized geometries at B3LYP/6-31G(d).

\begin{tabular}{|c|c|c|c|c|c|c|}
\hline Compounds & $\begin{array}{l}\text { Electronic } \\
\text { transitions }\end{array}$ & $\begin{array}{l}\lambda \mathrm{abs} \\
(\mathrm{nm})\end{array}$ & $\begin{array}{l}* \mathrm{E}_{\mathrm{ex}} \\
(\mathrm{eV})\end{array}$ & $* * \mathrm{O} . \mathrm{S}$ & $\mathrm{MO} /$ character & $\begin{array}{l}\lambda \max \\
\exp (n m)^{12}\end{array}$ \\
\hline M1 & $\begin{array}{l}\mathrm{S} 0 \rightarrow \mathrm{S} 1 \\
\mathrm{~S} 0 \rightarrow \mathrm{S} 2 \\
\mathrm{~S} 0 \rightarrow \mathrm{S} 3\end{array}$ & $\begin{array}{l}386.36 \\
379.85 \\
364.60\end{array}$ & $\begin{array}{l}3.20 \\
3.26 \\
3.40\end{array}$ & $\begin{array}{l}\mathbf{0 . 2 7} \\
0.00 \\
0.00\end{array}$ & $\begin{array}{l}\text { HOMO } \rightarrow \text { LUMO }(\mathbf{9 2 \%}) \\
\text { HOMO } \rightarrow \text { LUMO+1 }(79 \%) \\
\text { HOMO-2 } \rightarrow \text { LUMO+1 }(48 \%)\end{array}$ & - \\
\hline M2 & $\begin{array}{l}\mathrm{S} 0 \rightarrow \mathrm{S} 1 \\
\mathrm{~S} 0 \longrightarrow \mathrm{S} 2 \\
\mathrm{~S} 0 \rightarrow \mathrm{S} 3\end{array}$ & $\begin{array}{l}416.22 \\
\mathbf{3 9 5 . 8 8} \\
383.73\end{array}$ & $\begin{array}{l}2.97 \\
3.13 \\
3.23\end{array}$ & $\begin{array}{l}0.91 \\
\mathbf{0 . 9 9} \\
0.00\end{array}$ & $\begin{array}{l}\text { HOMO } \rightarrow \text { LUMO+1 }(83 \%) \\
\text { HOMO } \rightarrow \text { LUMO }(\mathbf{7 4 \%}) \\
\text { HOMO-6 } \rightarrow \text { LUMO+1 }(72 \%)\end{array}$ & - \\
\hline M3 & $\begin{array}{l}\mathrm{S} 0 \rightarrow \mathrm{S} 1 \\
\mathrm{~S} 0 \rightarrow \mathrm{S} 2 \\
\mathrm{~S} 0 \rightarrow \mathrm{S} 3\end{array}$ & $\begin{array}{l}426.38 \\
\mathbf{4 1 2 . 0 8} \\
\mathbf{3 8 3 . 5 2}\end{array}$ & $\begin{array}{l}2.90 \\
\mathbf{3 . 0 0} \\
3.23\end{array}$ & $\begin{array}{l}1.02 \\
\mathbf{1 . 1 2} \\
0.00\end{array}$ & $\begin{array}{l}\text { HOMO } \rightarrow \text { LUMO+1 }(77 \%) \\
\text { HOMO } \rightarrow \text { LUMO }(\mathbf{6 6 \%}) \\
\text { HOMO-6 } \rightarrow \text { LUMO+1 }(72 \%)\end{array}$ & $\sim 480$ \\
\hline M4 & $\begin{array}{l}\mathrm{S} 0 \rightarrow \mathrm{S} 1 \\
\mathrm{~S} 0 \rightarrow \mathrm{S} 2 \\
\mathrm{~S} 0 \rightarrow \mathrm{S} 3\end{array}$ & $\begin{array}{l}413.94 \\
\mathbf{3 9 1 . 0 2} \\
381.59\end{array}$ & $\begin{array}{l}2.98 \\
3.17 \\
3.21\end{array}$ & $\begin{array}{l}0.79 \\
\mathbf{0 . 9 8} \\
0.02\end{array}$ & $\begin{array}{l}\text { HOMO } \rightarrow \text { LUMO+1 }(80 \%) \\
\text { HOMO } \rightarrow \text { LUMO }(\mathbf{7 3 \%}) \\
\text { HOMO-8 } \rightarrow \text { LUMO+1 }(73 \%)\end{array}$ & $\sim 340$ \\
\hline
\end{tabular}

*E $\mathrm{E}_{\mathrm{ex}}$ : Excitation energy; **O.S: Oscillator strength

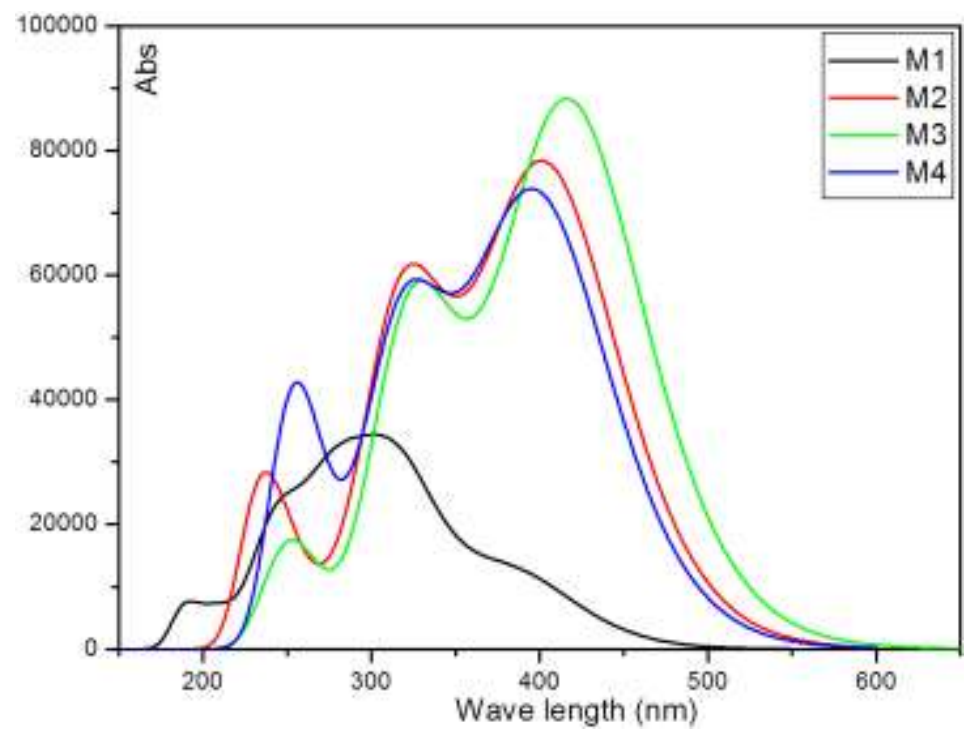

Figue 5. Simulated UV-visible optical absorption spectra of the studied compounds.

\section{Conclusion}

We show in this study a theoretical analysis using DFT and ZINDOs of the structural geometries, electronic and optical properties of four noncentrosymmetric hexaazatriphenylene derivatives compounds synthesized by Rafael Juarez et al.. 
The optimized structures for all the studied compounds indicate that all have quasi planar conformation. The corresponding band gap energies range from $3.30 \mathrm{eV}$ to $1.78 \mathrm{eV}$ and increases in the following order $\mathrm{M} 4<\mathrm{M} 3<\mathrm{M} 2<\mathrm{M} 1$.

Moreover, the LUMO energy of these compounds is higher than that of the PCBM and the calculated values of Voc range from 0.91 to $1.49 \mathrm{eV}$, providing sufficient thermodynamic driving for electron injection from the excited molecules to the acceptor (PCBM).

Finally, the procedures of these theoretical calculations can be employed to predict the electronic properties of further novel materials used for photovoltaic applications such as organic solar cells.

\section{Acknowledgements}

The authors are grateful to the "Association Marocaine des Chimistes Théoriciens (AMCT)" for help on computation software.

\section{References}

1- Helga Seyler, Balaji Purushothaman, David J. Jones, Andrew B. Holmes, and Wallace W. H. Wong, Pure Appl. Chem., 2012, 84, 4, 1047-1067.

2- (a) T. Hirayama, S. Yamasaki, H. Ameku, T. Ishi-i, T. Thiemann, S. Mataka, Dyes Pigmemts., 2005, 67, 105-110. (b) T. Ishi-i, K. Murakami, Y. Imai, S. Mataka. Org.Lett., 2005, 7, 15, 3175-3178.

3- (a) T. Ishi-I, K.Yaguna, R. Kuwahara, Y. Taguri, S. Mataka. Org. Lett., 2006, 8, 4, 585-588.

(b) T. Ishi-i, H.Tashiro, R. Kuwahara, S. Mataka, T. Yoshihara, S.Tobita. Chem. Lett., 2006, 35 , 158-159.

4- S. R. Marshall, A. L. Rheingold, L. N. Dawe, W. W. Shum, C. Kitamura, J.S. Miller, Inorg. Chem., 2002, 41, 14, 3599-3601.

5- D. J. Gundlach, J. E. Royer, S. K. Park, S.Subramanian, O. D. Jurchescu, B. H. Hamadani, A. J. Moad, R. J. Kline, L. C. Teague, O. Kirillov, C. A. Richter, J. G Kushmerick, L. J. Richter, S. R. Parkin, T. N. Jackson, J. E. Anthony, Nat. Mater, 2008,7, 216-221.

6- S. K. Park, T. N. Jackson, J. E. Anthony, D. A. Mourey, Appl. Phys. Lett., 2007, 91, 063514 063517.

7- C. D. Simpson, J. Wu, M. D. Watson, and K. M. llen, J. Mater. Chem., 2004, 14, 494-504.

8- (a) S. Kitagawa, S. Masaoka, Chem. Rev., 2003, 246, 73-88; (b) Z.Y. Xiao, X. Zhao, X.K. Jiang, Z. T. Li, Chem. Mater., 2011, 23, 1505-1511.

9- B. R. Cho, S.K. Lee, K.A. Kim, T.I. Kang, S. J. Jeon. Tetrahedron Lett., 1998, 39, 9205-9208
10- (a) C.W. Ong, S.C. Liao, T.H. Chang, H.F. Hsu. J.Org. Chem., 2004, 69, 9,3181-3185. (b) M. Lehmann, V. Lemaur, J. Cornil, J.L. Bredas, S. Goddard, I. Grizzi, Y. Geerts .Tetrahedron., 2004, 60, 3283-3291.

11- (a) T. Ishi-I, K. Yaguna, R. Kuwahara, Y. Taguri S. Mataka. Org. Lett., 2006, 8, 585588. (b) T. Ishi-i, H. Tashiro, R. Kuwahara, S. Mataka, T. Yoshihara, S. Tobita. Chem. Lett., 2006, 35, 158-159.

12- R. Juarez, M. M. Ramos and J. L. Segura. Tetrahedron Letters., 2007, 488829-48833.

13- J.A. Mikroyannidis, D.V. Tsagkournos, P. Balraju, G.D. Sharma. Journal of Power Sources., 2011, 196, 8,4152-4161.

14- V.A. Rassolov, M.A. Ratner, J.A. Pople, P.C. Redfern, L.A. Curtiss, J. Comp. Chem., 2001, 22 , 976-984.

15- M. J. Frisch, G. W. Trucks, H. B. Schlegel, G. E. Scuseria, M. A. Robb, J. R. Cheeseman, Jr. J. A. Montgomery, T. Vreven, K. N. Kudin, J. C. Burant, J. M. Millam, S. S. Iyengar, J. Tomasi, V. Barone, B. Mennucci, M. Cossi, G. Scalmani, N. Rega, G. A. Petersson, H. Nakatsuji, M. Hada, M. Ehara, K. Toyota, R. Fukuda, J. Hasegawa, M. Ishida, T. Nakajima, Y. Honda, O. Kitao, H. Nakai, M. Klene, X. Li, J. E. Knox, H. P. Hratchian, J. B. Cross, V. Bakken, C. Adamo, J. Jaramillo, R. Gomperts, R. E. Stratmann, O. Yazyev, A. J. Austin, R. Cammi, C. Pomelli, J. W. Ochterski, P. Y. Ayala, K. Morokuma, G. A. Voth, P. Salvador, J. J. Dannenberg, V. Zakrzewski, G. S.Dapprich, A. D. Daniels, M. C. Strain, O. Farkas, D. K. Malick, A. D. Rabuck, K.. Raghavachari, J. B. Foresman, J. V. Ortiz, Q. Cui, A. G. Baboul, S. Clifford, J. Cioslowski, B. B. Stefanov, G. Liu, A. Liashenko, P. Piskorz, I. Komaromi, R. L. Martin, D. J. Fox, T. Keith, M. A. Al-Laham, C. Y. Peng, A. Nanayakkara, M. Challacombe, P. M. W. Gill, B. Johnson, W. Chen, M. W. Wong, C. Gonzalez, J. A. Pople, GAUSSIAN 09, Revision B.04, Gaussian: Pittsburgh, PA, 2009.

16- J. B. Foresman, M. Head-Gordon, J. A. Pople, M. J. Frisch, J. Chem. Phys., 1992, 96, 135-149.

17- M. Bouachrine, A. Echchary, S.M. Bouzzine, M. Amine, M. Hamidi M, A. Amine, T. Zair. Phys, Chem. News., 2011, 58 : 61- 66.

18- L. Yang, J. Feng, A. Ren, Polymer., 2005, 46, 10970-10981.

19- J. B. Asbury, YQ. Wang Y, E. Hao, H. Ghosh, T. Lian. Res. Chem. Intermed., 2001, 27, 393- 406.

20- (a) Z. L. Wu, B. H. Fan, F. Xue, C. Adachi, J. Y. Ouyang, Energy Mater. Sol. Cells., 2010, 94, 2230-2237. (b) A. Gadisa, M. Svensson, M. R. Andersson, O. Inganas, Appl. Phys. Lett., 2004, 84,9, 1609-1611. 